\title{
DIRECT FEM LARGE SCALE COMPUTATION OF TURBULENT MULTIPHASE FLOW IN URBAN WATER SYSTEMS AND MARINE ENERGY (ECCOMAS CONGRESS 2016)
}

\author{
EZHILMATHI KRISHNASAMY ${ }^{1}$, JOHAN HOFFMAN ${ }^{12}$, and JOHAN JANSSON ${ }^{1} 2$ \\ ${ }^{1}$ BCAM - Basque Center for Applied Mathematics \\ Mazarredo 14, 48009 Bilbao, Spain \\ e-mail: ekrishnasamy@ bcamath.org \\ ${ }^{2}$ Department of High Performance Computing and Visualization KTH Royal Institute of Technology \\ SE-10044, Stockholm, Sweden \\ e-mail: \{jjan,jhoffman\}@kth.se
}

Keywords: Adaptive, FEM, Turbulence, Marine Engineering.

\begin{abstract}
High-Reynolds number turbulent incompressible multiphase flow represents a large class of engineering problems of key relevance to society. Here we describe our work on modeling two such problems:

1. The Consorcio de Aguas Bilbao Bizkaia is constructing a new storm tank system with an automatic cleaning system, based on periodically flushing tank water out in a tunnel.

2. In the framework of the collaboration between BCAM - Basque Center for Applied Mathematics and Tecnalia $R \& I$, the interaction of the sea flow with a semi submersible floating offshore wind platform is computationally investigated. Here we study the MARIN benchmark modeling breaking waves over objects in marine environments.

Both of these problems are modeled in the the Direct FEM/General Galerkin methodology for turbulent incompressible variable-density flow [1] 2]
\end{abstract}




\section{Introduction}

Today world is facing the global warming by anthropogenic activities and natural disaster(e.g., earthquake, tsunami and volcano) which are causing ozone layer depletion, loss of biodiversity, water quality and climate change. Among these climate change causes extreme weather phenomena across the world, resulting either severe flood or draught. In 20th century about 1000000 people were killed and 1.4 billion people were affected by the floods[3]. Floods not only kills and affects the people and also it affects the eco-system, agriculture production, infrastructure and creates economical instability. According to The International Disaster Database [4], from January 1975 to June 2002, flash floods (due to heavy rain) in Europe has 5.6 $\%$ morality (rate of killed verses affected people) [3]. Especially, in Spain from 1900 to 2016, flash flood killed 987 people, 1350 people were affected and it caused damage of 642000000 $\$$ [4]. And it is predicted that the weather instability (more flash floods) going to be happen frequently in coming years [5].

Bilbao is located northern part of Spain and it has oceanic/Atlantic climate; its annual precipitation is from 1200 to 2000 millimeter (mm)[6]. Consorcio de Aguas Bilbao Bizkaia (BWC) is constructing a new storm tank (detention tank) system with an automatic cleaning system, based on periodically flushing tank out in a tunnel in Galindo. This would prevent rain water goes into river and also minimize the more hydraulic load on the existing sewer infrastructure. Later this water can be treated in waste water treatment plant (WWTP) in Galindo for portable or other purposes.

The excessive water from the detention tank overflows through the tunnel, where the sediments and floating objects might permanently settle down on the surface of the tunnel, which will eventually give the foul smell and in a frequent run it will also affect the downstream flow in the tunnel. It is not a feasible solution to send a men to clean the tunnel. Instead BWC wants to clean the tunnel with periodic flushing using water from the detention tank.

Our work in the research is to predict the velocity, pressure and flow rate in the down stream side of the tunnel. Where this velocity, pressure and flow rate values will be used as a input parameter for the shallow water modelling; and also velocity at the door section will be used to design the stronger gate to open a water from the detention tank. We used the Finite Element Method (FEM) for the simulation calculation, problem is modelled as a 3D computations of the primitive equations (variable-density incompressible Navier-Stokes) in FEniCS-HPC.

For the simulation, we have investigated the 4 options, they are: $T_{D}=5 \mathrm{~s}, 10 \mathrm{~s}$ and $\mathrm{H}=6 \mathrm{~m}, 10 \mathrm{~m}$, with $T_{D}$ the time for the door to fully open and $\mathrm{H}$ the initial water height in the tank. We compute the time interval $\mathrm{I}=[0 \mathrm{~s}, 6 \mathrm{~s}]$ for $T_{D}=5 \mathrm{~s}$, and $\mathrm{I}=[0 \mathrm{~s}, 11 \mathrm{~s}]$ for $T_{D}=10 \mathrm{~s}$.

\section{Mathematical model}

We model the problem by the primitive incompressible Navier-Stokes equations with variable density $\rho$ :

$$
\begin{aligned}
R(\hat{u}) & =\left\{\begin{array}{l}
\rho\left(\partial_{t} u+(u \cdot \nabla) u\right)+\nabla p-\nu \Delta u-\rho g=0 \\
\partial_{t} \rho+(u \cdot \nabla) \rho=0 \\
\nabla \cdot u=0
\end{array}\right. \\
\hat{u} & =(u, p, \rho)
\end{aligned}
$$

By using a parameter-free stabilized finite element method (FEM) we are not introducing any explicit parametrization or modeling, aside from the slip model of the boundary layer, 
and we thus expect the simulations to be predictive if the mesh is fine enough to control the computational error.

\subsection{Turbulent boundary layers}

In our work on high Reynolds number turbulent flow [7, 8, 9, 10, 11], we have chosen to apply a skin friction stress as wall layer model. That is, we append the Navier-Stokes equations (NSE) with the following boundary conditions:

$$
\begin{aligned}
& u \cdot n=0, \\
& \beta u \cdot \tau_{k}+n^{T} \sigma \tau_{k}=0, \quad k=1,2,
\end{aligned}
$$

for $(x, t) \in \Gamma_{\text {solid }} \times I$, with $n=n(x)$ an outward unit normal vector, and $\tau_{k}=\tau_{k}(x)$ orthogonal unit tangent vectors of the solid boundary $\Gamma_{\text {solid. }}$. We use matrix notation with all vectors $v$ being column vectors and the corresponding row vector is denoted $v^{T}$.

With skin friction boundary conditions, the rate of kinetic energy dissipation in $\mathrm{cG}(1) \mathrm{cG}(1)$ has a contribution of the form (for constant density):

$$
\sum_{k=1}^{2} \int_{0}^{T} \int_{\Gamma_{\text {solid }}}\left|\beta^{1 / 2} \bar{U} \cdot \tau_{k}\right|^{2} d s d t
$$

from the kinetic energy which is dissipated as friction in the boundary layer. For high $R e$, we model $R e \rightarrow \infty$ by $\beta \rightarrow 0$, so that the dissipative effect of the boundary layer vanishes with large $R e$. In particular, we have found that a small $\beta$ does not influence the solution [9]. For the present simulations we used the approximation $\beta=0$, which can be expected to be a good approximation for the high Reynolds numbers expected for the present setting.

\section{Computational methodology and software}

The mathematical framework for the simulation method is functional analysis and the concept of weak solutions to the NSE, introduced by the mathematician Jean Leray in 1934. Leray proved that there exist weak solutions (or turbulent solutions in the terminology of Leray) that satisfy NSE in variational form, that is NSE integrated against a family of test functions.

A finite element method (FEM) is based on the variational form of NSE, and one can show that, if the formulation of the method satisfies certain conditions on stability and consistency, the approximate FEM solutions converge towards a weak solution of the NSE as the finite element mesh is refined [12]. We refer to such FEM as General Galerkin (G2) methods.

The test functions in G2 are defined over the mesh, and thus the finest scales of a G2 approximation are set by the mesh size. In contrast to RANS or LES (Large eddy simulation), no averaging operator or filter is applied to NSE, and thus no Reynolds or subgrid stresses that need modeling are introduced. Dissipation of turbulent kinetic energy in under-resolved parts of the flow is provided by the numerical stabilization of G2 in the form of a weighted least squares method based on the residual of NSE. Thus, the method is purely based on the NSE mathematical model, and no other modeling assumptions are made.

In $\mathrm{G} 2$, the mesh is adaptively constructed based on a posteriori estimation of the error in chosen goal or target functionals, such as drag and lift forces for example. Using duality in a variational framework, a posteriori error estimates can be derived in terms of the residual, the mesh size, and the solution of a "dual" (or "adjoint") problem [13]. We initiate the adaptive 
mesh refinement algorithm from a coarse mesh, fine enough to capture the geometry, but without any further assumptions on the solution (i.e., no boundary layer meshes or ad hoc mesh design based on expected separation and wake structures are needed).

To model the effect of unresolved turbulent boundary layers we use a simple parametrization of the wall shear stress in terms of the skin friction [14]. In particular, for the very high $R e$ for this problem we approximate the small skin friction by zero skin friction, which corresponds to a free slip boundary condition without boundary layer resolution.

This methodology is validated for a number of standard benchmark problems in the literature [15, 16, 17, 18], and in the following sections we describe the basic elements of the G2 method, also referred to as Adaptive DNS/LES, or simply Direct Finite element Simulation (DFS).

For this particular problem of the storm drain, we have used a low order finite element discretization on unstructured tetrahedral meshes, which we refer to as $\mathrm{cG}(1) \mathrm{cG}(1)$, i.e., continuous piecewise linear approximations in space and time. In this project we have not applied adaptive mesh refinement, since it currently only is functional for production simulations for constant density. The development of this functionality is expected to be done over the coming year.

\subsection{Direct FEM for variable-density}

In a $\mathrm{cG}(1) \mathrm{cG}(1)$ method [12] we seek an approximate space-time solution $\hat{U}=(D, U, P)$ (with $D$ the discrete density $\rho$ ) which is continuous piecewise linear in space and time (equivalent to the implicit Crank-Nicolson method). With $I$ a time interval with subintervals $I_{n}=$ $\left(t_{n-1}, t_{n}\right), W^{n}$ a standard spatial finite element space of continuous piecewise linear functions, and $W_{0}^{n}$ the functions in $W^{n}$ which are zero on the boundary $\Gamma$, the $\mathrm{cG}(1) \mathrm{cG}(1)$ method for variable-density incompressible flow with homogeneous Dirichlet boundary conditions for the velocity takes the form: for $n=1, \ldots, N$, find $\left(D^{n} U^{n}, P^{n}\right) \equiv\left(D\left(t_{n}\right), U\left(t_{n}\right), P\left(t_{n}\right)\right)$ with $D^{n} \in W^{n}, U^{n} \in V_{0}^{n} \equiv\left[W_{0}^{n}\right]^{3}$ and $P^{n} \in W^{n}$, such that

$$
\begin{aligned}
& r(\hat{U}, \hat{v})=\left(D\left(\left(U^{n}-U^{n-1}\right) k_{n}^{-1}+\left(\bar{U}^{n} \cdot \nabla\right) \bar{U}^{n}\right), v\right)+\left(2 \nu \epsilon\left(\bar{U}^{n}\right), \epsilon(v)\right) \\
& \left.\left.-(P, \nabla \cdot v)-(D g, v)+\left(\nabla \cdot \bar{U}^{n}, q\right)+\left(D^{n}-D^{n-1}\right) k_{n}^{-1}+\left(\bar{U}^{n} \cdot \nabla\right) \bar{D}^{n}\right), v\right) \\
& +L S(D, U, P)+S C(D, U, P)=0, \forall \hat{v}=(z, v, q) \in W^{n} \times V_{0}^{n} \times W^{n}
\end{aligned}
$$

where $\bar{U}^{n}=1 / 2\left(U^{n}+U^{n-1}\right)$ is piecewise constant in time over $I_{n}$ and LS and SC are leastsquares and shock-capturing stabilizing term described in [12].

\subsection{The FEniCS-HPC finite element computational framework}

The simulations in this report have been computed using the Unicorn solver in the FEniCSHPC automated FEM software framework.

FEniCS-HPC is an open source framework for automated solution of PDE on massively parallel architectures, providing automated evaluation of variational forms given a high-level description in mathematical notation, duality-based adaptive error control, implicit parameterfree turbulence modeling by use of stabilized FEM and strong linear scaling up to thousands of cores [19, 20, 21, 22, 23, 24]. FEniCS-HPC is a branch of the FEniCS [25, 26] framework focusing on high performance on massively parallel computer architectures.

Unicorn is solver technology (models, methods, algorithms and software) with the goal of automated high performance simulation of realistic continuum mechanics applications, such as drag or lift computation for fixed or flexible objects (FSI) in turbulent incompressible or compressible flow. The basis for Unicorn is Unified Continuum (UC) modeling [27] formulated 
in Euler (laboratory) coordinates, together with the General Galerkin (G2) adaptive stabilized finite element discretization described above.

\section{The MARIN becnhmark problem}

A standard benchmark in marine engineering for a wave impact or dam break is the MARIN benchmark [29], consisting of a door opening, releasing a volume of water and creating a wave which impacts a box, representing for example a container on a ship. Pressure sensors are mounted on the box, providing validation data.

We apply the Direct FEM method for variable density described above to the MARIN benchmark using a tetrahedral mesh with approximately uniform mesh size and ca. 2 million vertices.

In figure 1 we visualize the density for regular time points in the time interval, showing the evolution of the water surface. In figure 2 the pressure signal for pressure sensors P1 and P7 are compared between the simulation and experiment.
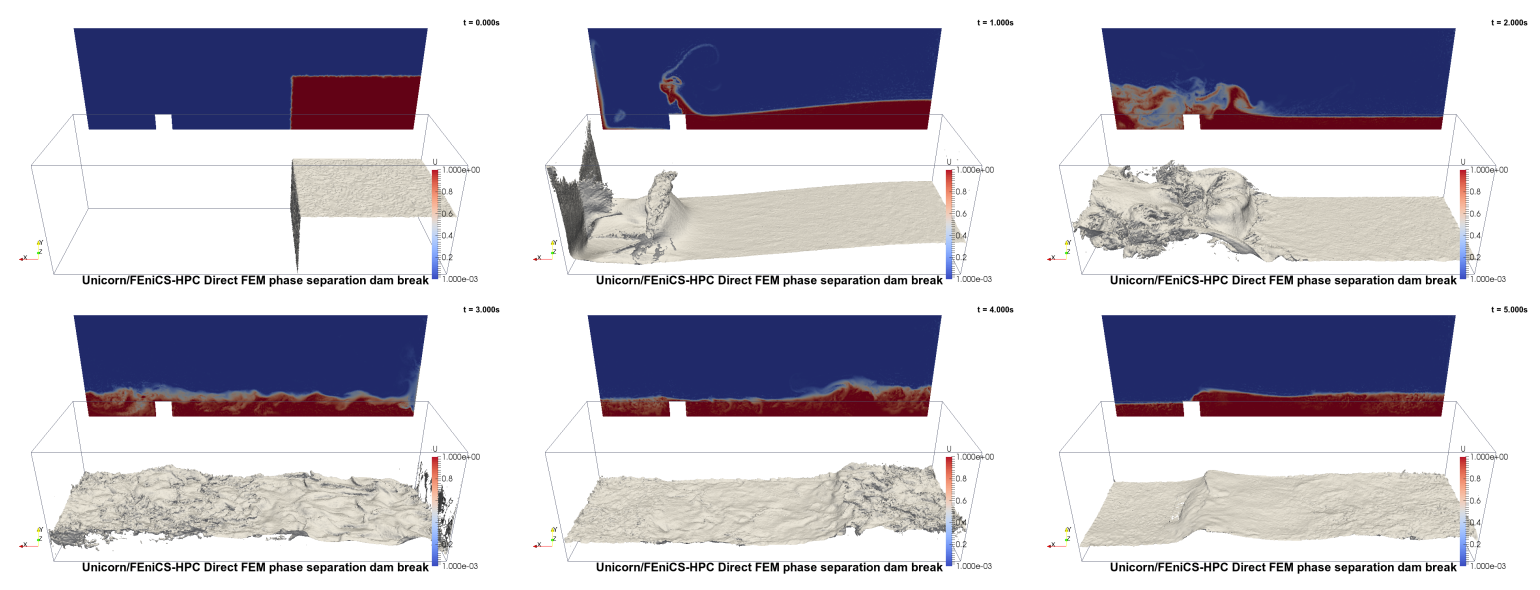

Figure 1: Density slice and isosurface for $\rho=0.5$ at $t=0,1,2,3,4,5 s$.

\section{The Bilbao Water Consortium storm drain problem}

The problem consistes of an initial water volume stored in a tank with a gate opening toward a storm drain tunnel. To clean the tunnel, the gate is opened, and water flows out throughout the tunnel. Here we investigate a range of gate opening speeds and initial water height in the tank.

The geometry of the tank, door and start of the tunnel is presented in figure 3 . The mesh is refined close to the door of the tank, and in the region with $\mathrm{x}$ coordinate $[30 \mathrm{~m}, 40 \mathrm{~m}]$ at the start of the tunnel, giving ca. 800k mesh points. The door height is $1 \mathrm{~m}$ and breadth is $6 \mathrm{~m}$. A slice of the mesh is presented in figure 4 demonstrating the distribution of the cell size.

Gravitational force $9.81 \mathrm{~m} \mathrm{~s}^{-1}$ is set at top of the tank and $0 \mathrm{~Pa}$ is set at the end of the tunnel. Walls in the geometry at the upstream \& downstream side considered as a free-slip boundary condition. The rest of the space in the geometry (tank and tunnel) were set to air density at ambient temperature as well as water density is set to the water in the tank. We set time interval as $0.02 \mathrm{~s}$, for example, in $T_{D}=5 \mathrm{~s}$, we get 250 time interval samples. The door opening mechanism is based on the time interval(0.02s). In this case, for each time sample, the door is moving (flow region space is gradually increasing) $0.004 \mathrm{~m}$ (total length for gate opening is $1 \mathrm{~m}$ ) towards upward vertical direction. Figure 5 shows the boundary and initial conditions set up in the simulation. 
Dam break pressure comparison Direct FEM sim. vs. MARIN exp.

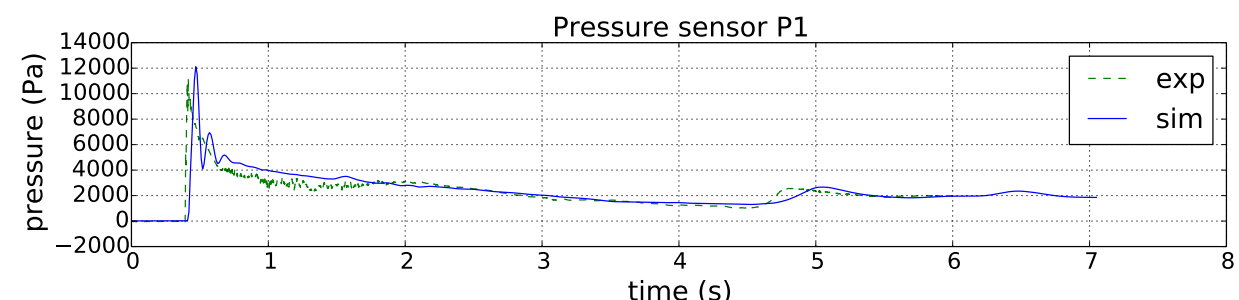

Pressure sensor $\mathrm{P} 7$

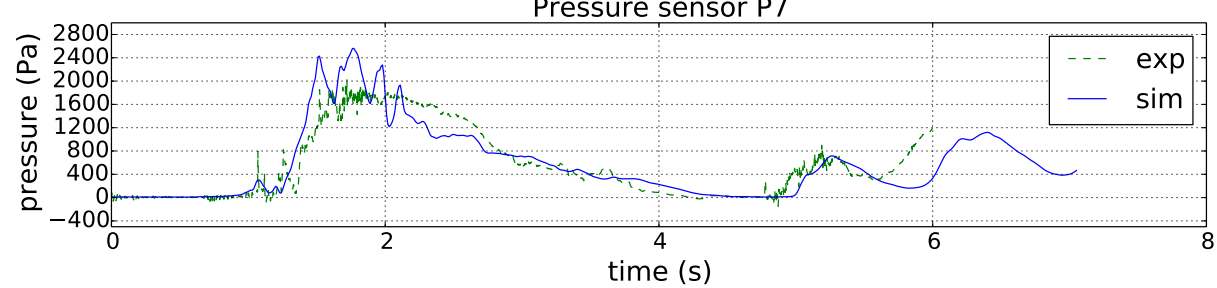

Figure 2: Pressure over time for simulation and experiment for the sensors P1 and P7 in the MARIN becnhmark.
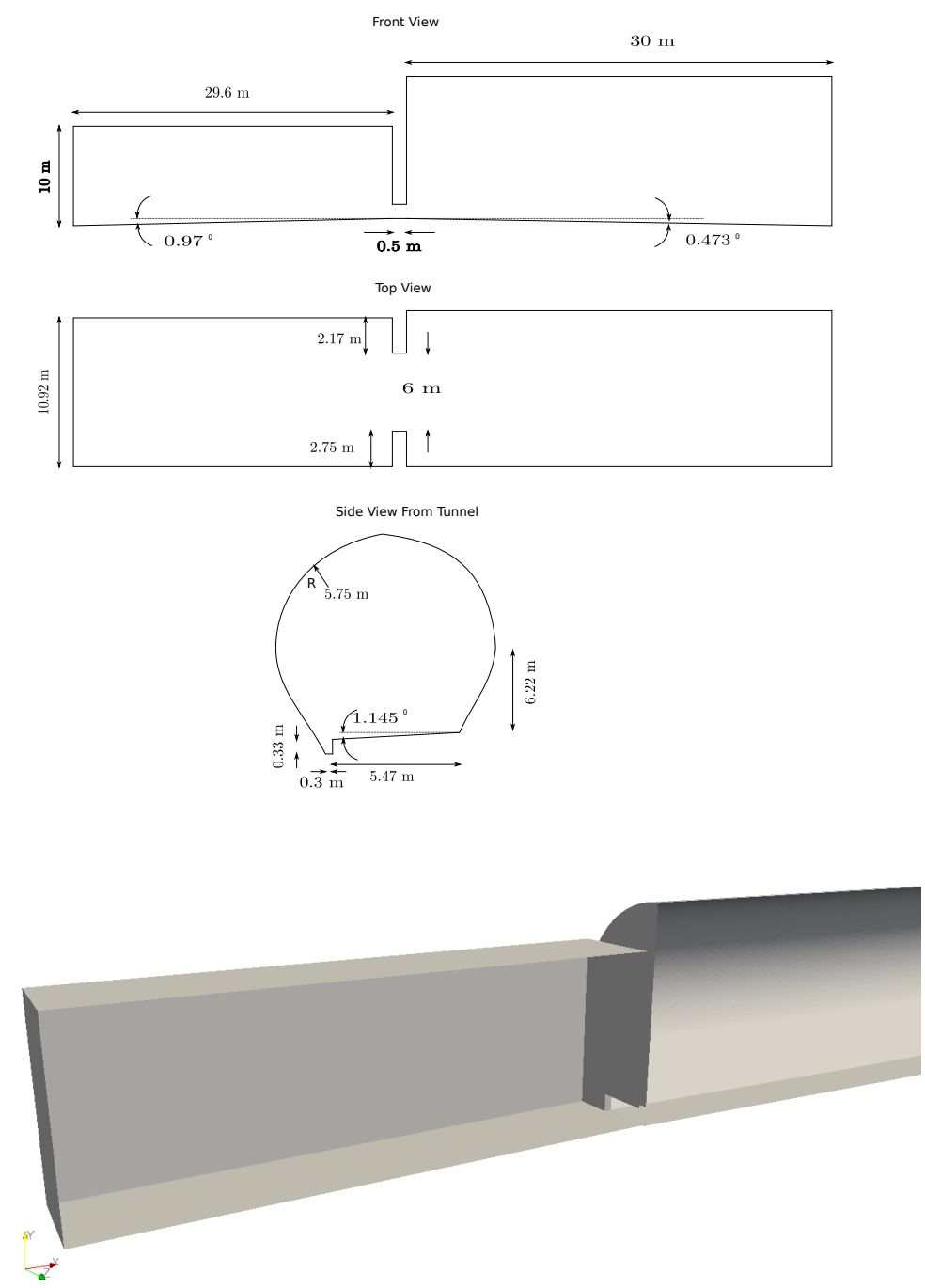

Figure 3: Schematic of the geometry of the tank, door and start of the tunnel (top), and a 3D rendering (bottom). 


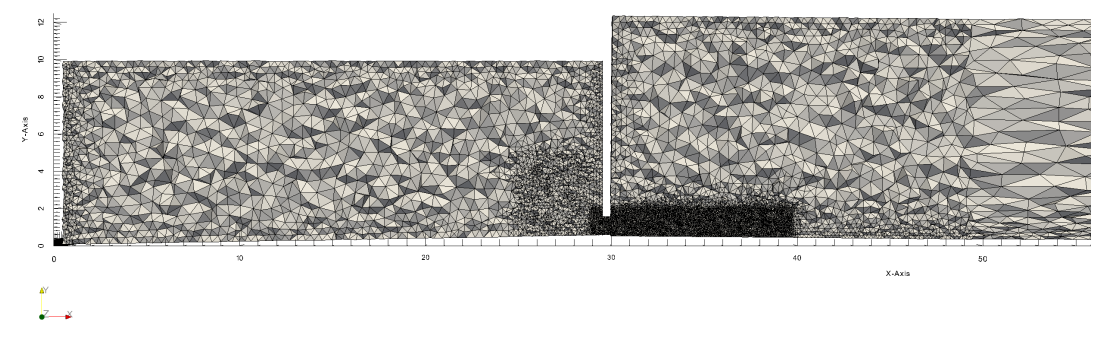

Figure 4: Slice plot through the $\mathrm{x}-\mathrm{z}$ plane (front view) of the mesh.

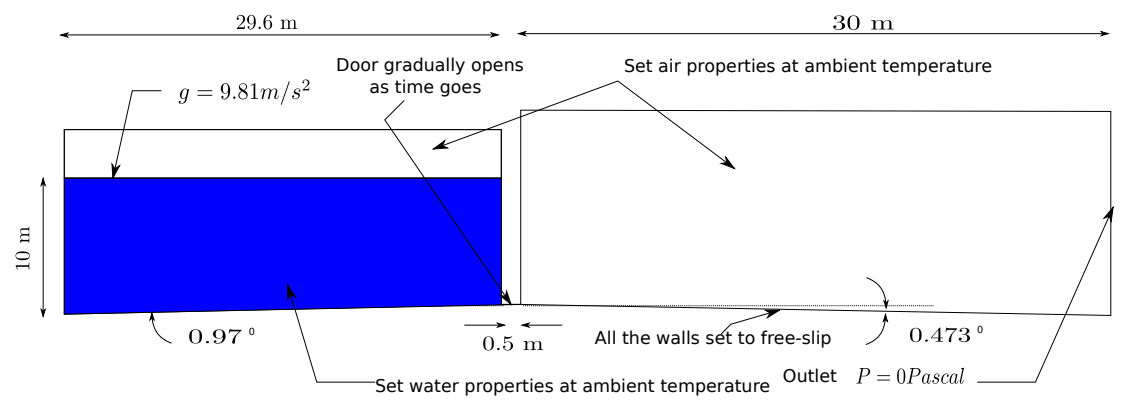

Figure 5: Initial and boundary conditions set up.

\subsection{Simulation results}

The simulations are carried out by running the FEniCS-HPC software on the Beskow supercomputer. The output is a piecewise linear density field representing the density of air and water, and a velocity field for the entire continuum. An average time step of ca. $k=5 \times 10^{-4}$ is chosen, giving ca. $10 \mathrm{k}$ time steps for $T_{D}=5 \mathrm{~s}$ and $20 \mathrm{k}$ time steps for $T_{D}=10 \mathrm{~s}$. We used 1024 cores on the Beskow Cray XC40 system at KTH for each simulation, giving ca. 1s per time step of computation time.

In this section we plot slice plots of the density (showing the evolution of the water surface), the velocity, 3D plots of the isovolume of the density (showing the evolution of the water surface). Additionally we plot the flow rate through the door over time, and the average velocity in the door section and in the first $10 \mathrm{~m}$ section of the tunnel.

For example, Figure 6 shows the initial condition of the simulation, where the water is stagnant and has a density; and the rest of the tank and tunnel have a air density. Since water is stagnant at this stage there is no flow movement in the problem domain. In Figure 7) After 5s, when the gate is fully opened, water flows through the tunnel, until for some distance the flow is steady after that it starts to break. This also can be seen water isovolume in Figure 9 .

To see better understanding of the simulation results, we extended the time upto $T D=6 \mathrm{~s}$ for $T D=5 \mathrm{~s}$. If the simulation stops at 5 th second, then we only get simulation results upto $4 \mathrm{~s}$. Figure 8 shows the visualization of the simulation until beginning of $T D=6 \mathrm{~s}$.

We can see the water flow pattern difference between water height in the tank $H=6 \mathrm{~m}$ to $H=10 \mathrm{~m}$ for $T D=6 \mathrm{~s}$ in Figures $12 \& 8$. For the $H=10 \mathrm{~m}$ the steady flow breaks earlier and it shows more turbulence behaviour than one in $H=6 \mathrm{~m}$. 
The noticeable difference between the $T D=5 \mathrm{~s}$ to $T D=10 \mathrm{~s}$ is that the downstream has a extended flow pattern, until it reaches the steady state condition. For example, this difference can be seen in Figures 12 \& 20.
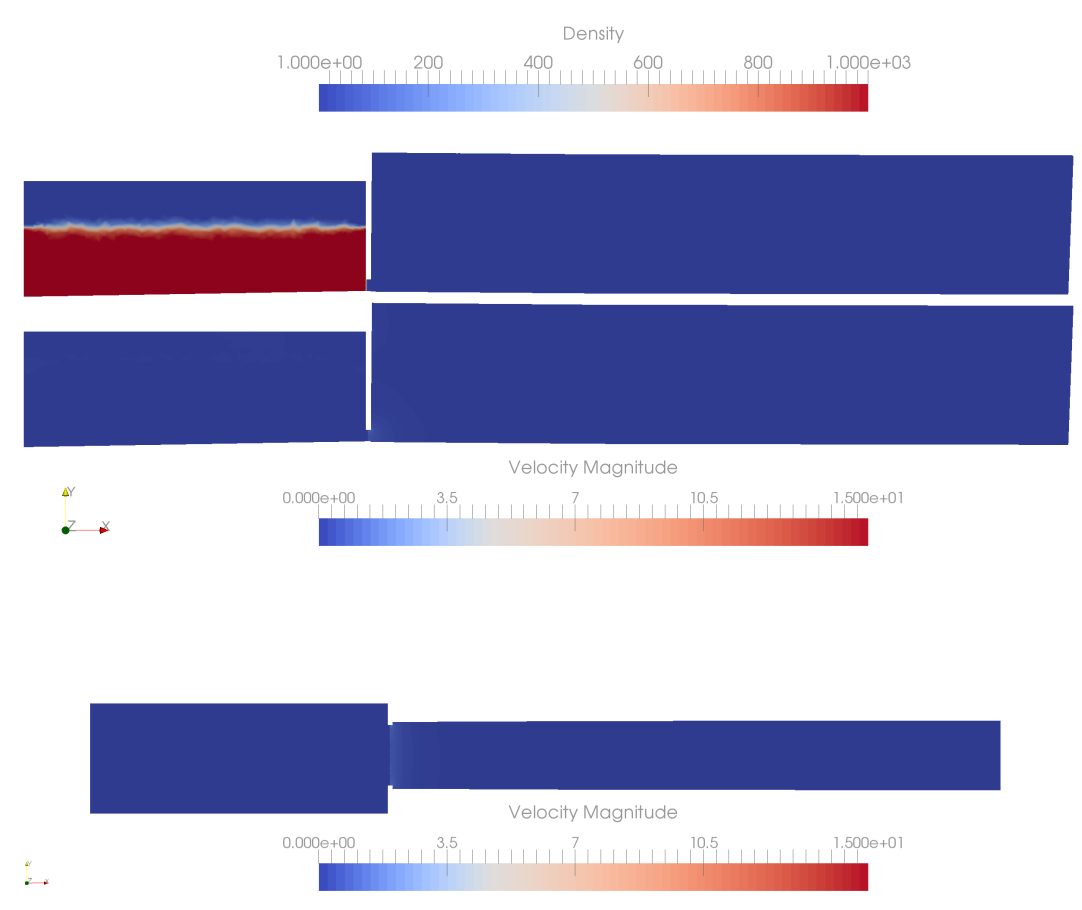

Figure 6: Density and velocity $\mathrm{x}-\mathrm{y}$ and $\mathrm{x}-\mathrm{z}$ slice $T_{D}=5 \mathrm{~s}, \mathrm{H}=6 \mathrm{~m}, \mathrm{t}=0 \mathrm{~s}$
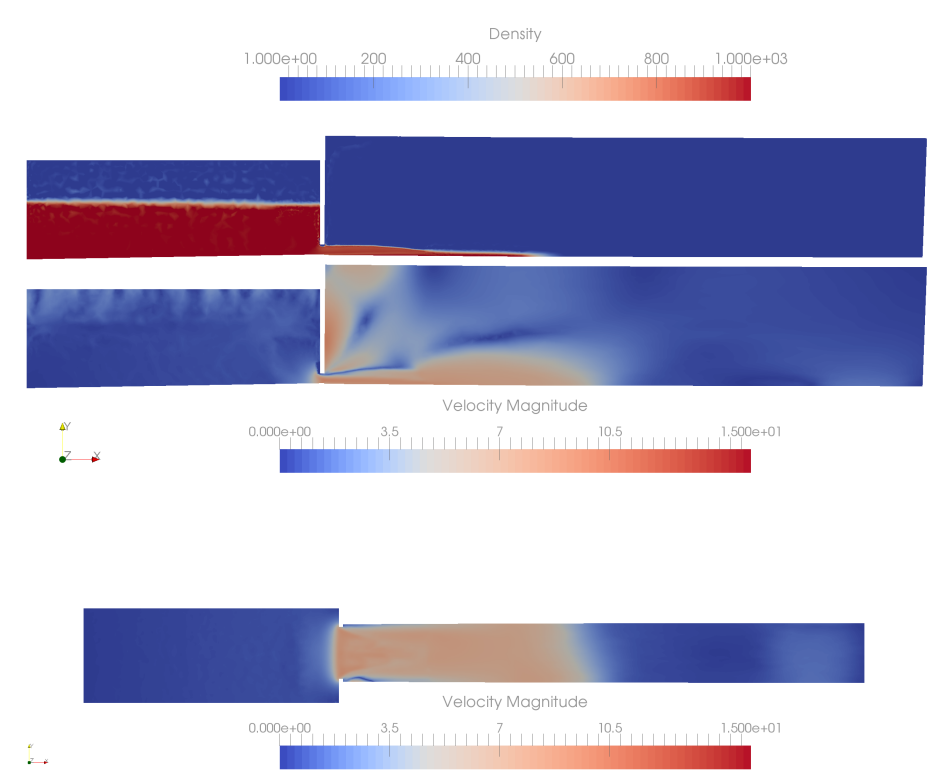

Figure 7: Density and velocity $\mathrm{x}-\mathrm{y}$ and $\mathrm{x}-\mathrm{z}$ slice $T_{D}=5 \mathrm{~s}, \mathrm{H}=6 \mathrm{~m}, \mathrm{t}=5 \mathrm{~s}$ 

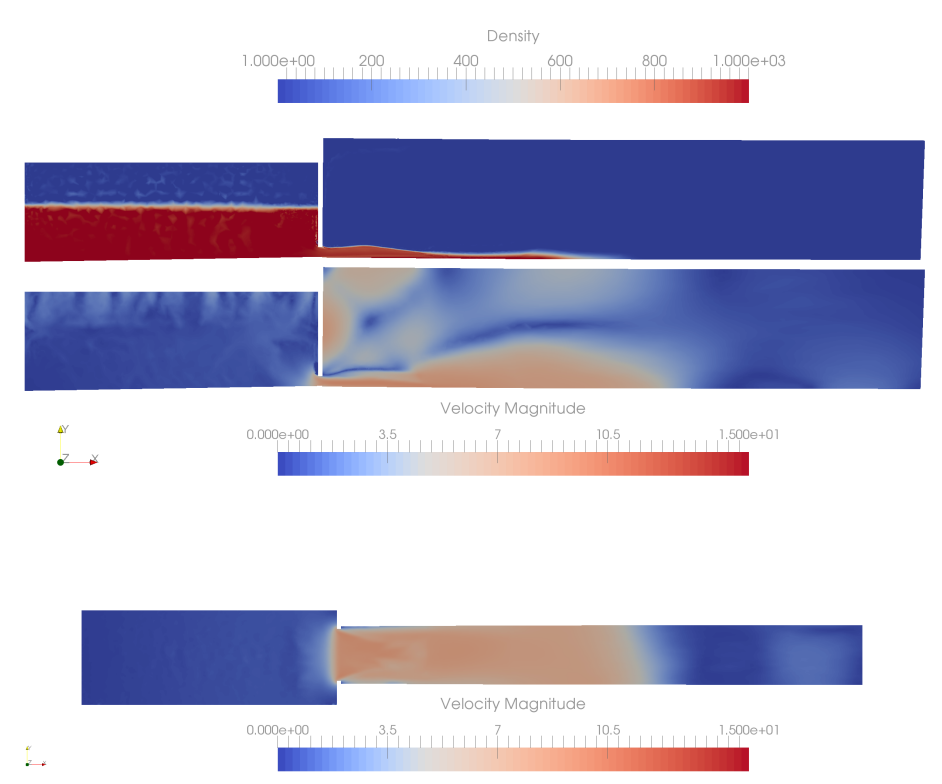

Figure 8: Density and velocity $\mathrm{x}-\mathrm{y}$ and $\mathrm{x}-\mathrm{z}$ slice $T_{D}=5 \mathrm{~s}, \mathrm{H}=6 \mathrm{~m}, \mathrm{t}=6 \mathrm{~s}$

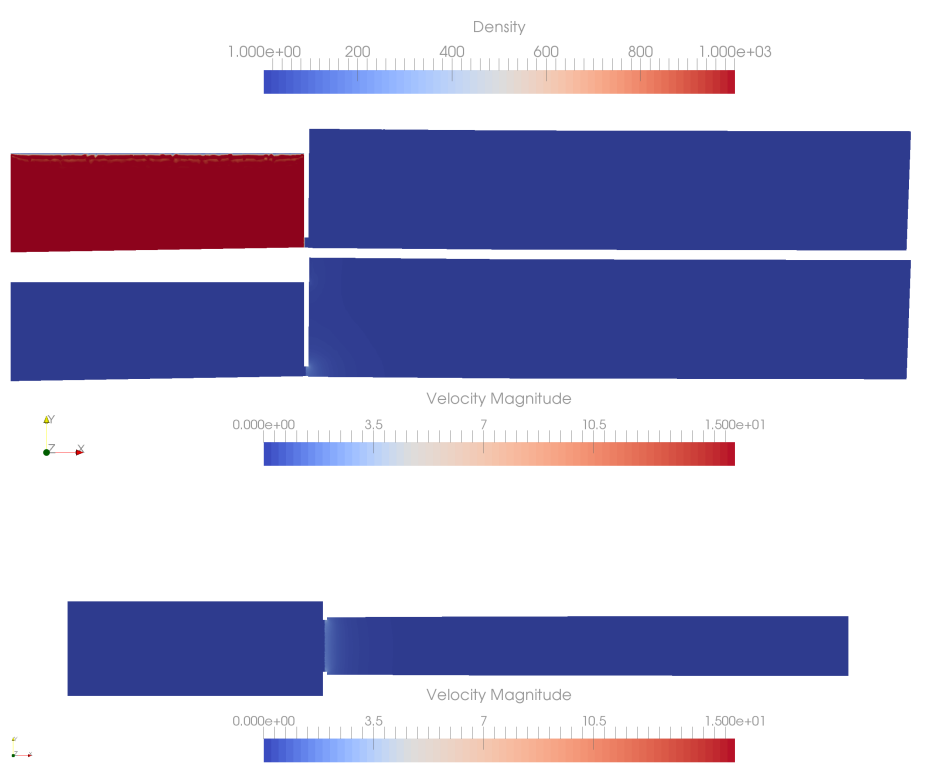

Figure 10: Density and velocity $\mathrm{x}-\mathrm{y}$ and $\mathrm{x}-\mathrm{z}$ slice $T_{D}=5 \mathrm{~s}, \mathrm{H}=10 \mathrm{~m}, \mathrm{t}=0 \mathrm{~s}$ 

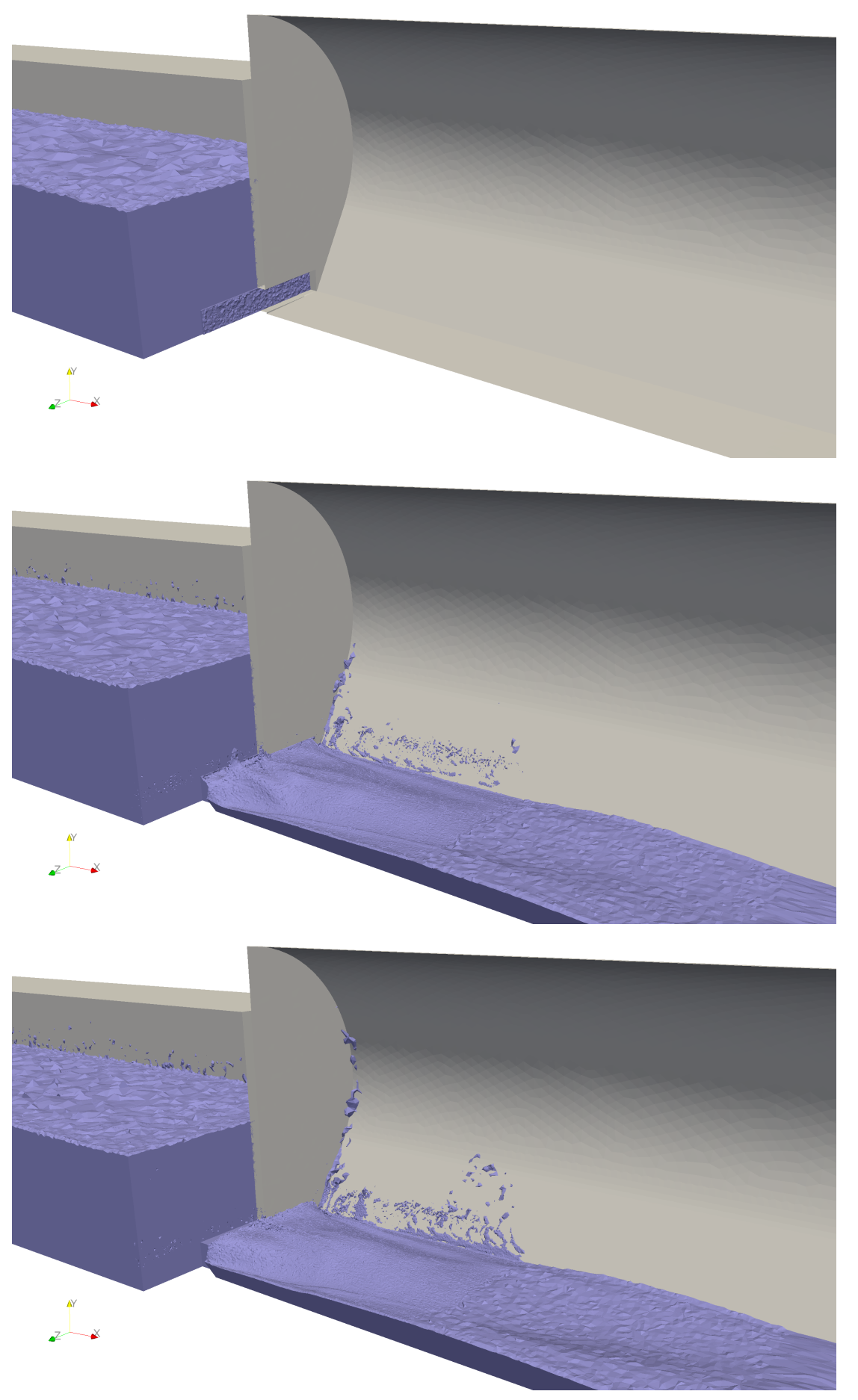

Figure 9: Water isovolume $T_{D}=5 \mathrm{~s}, \mathrm{H}=6 \mathrm{~m}, \mathrm{t}=\{0 \mathrm{~s}, 5 \mathrm{~s}, 6 \mathrm{~s}\}$ 

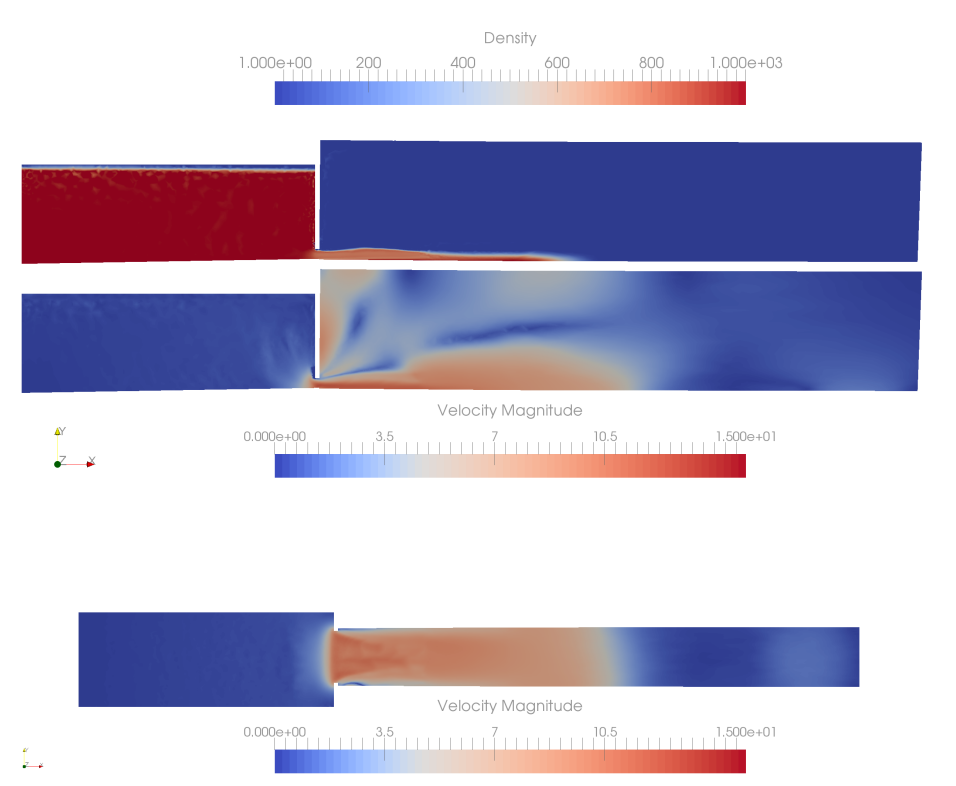

Figure 11: Density and velocity $\mathrm{x}-\mathrm{y}$ and $\mathrm{x}-\mathrm{z}$ slice $T_{D}=5 \mathrm{~s}, \mathrm{H}=10 \mathrm{~m}, \mathrm{t}=5 \mathrm{~s}$
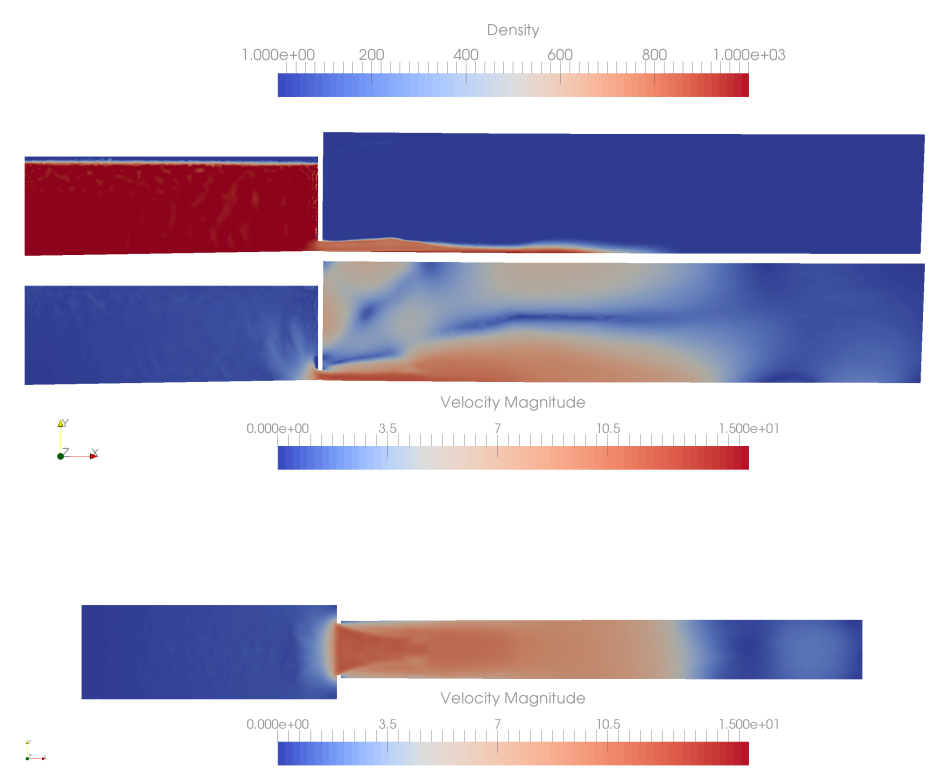

Figure 12: Density and velocity $\mathrm{x}-\mathrm{y}$ and $\mathrm{x}-\mathrm{z}$ slice $T_{D}=5 \mathrm{~s}, \mathrm{H}=10 \mathrm{~m}, \mathrm{t}=6 \mathrm{~s}$ 

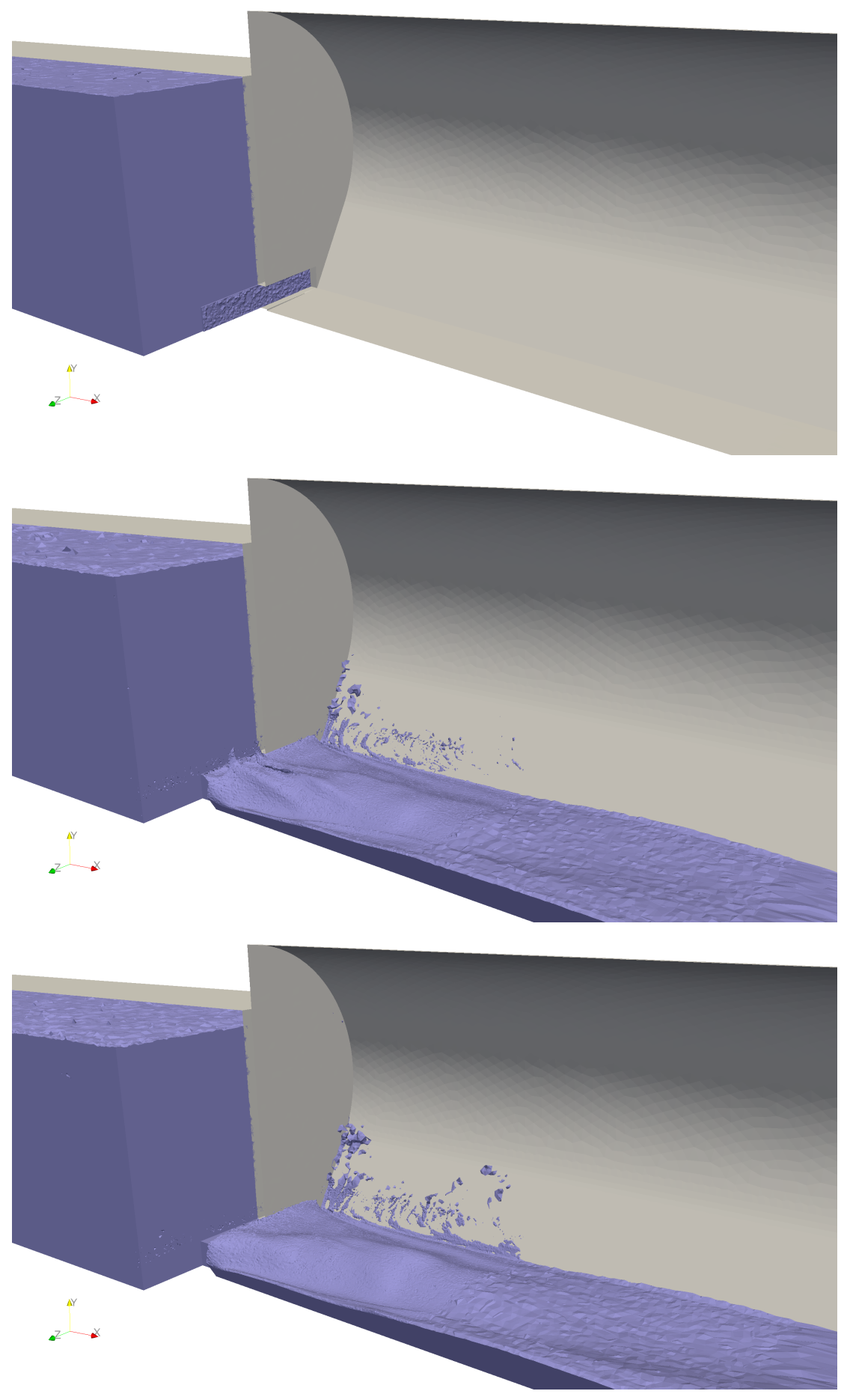

Figure 13: Water isovolume $T_{D}=5 \mathrm{~s}, \mathrm{H}=10 \mathrm{~m}, \mathrm{t}=\{0 \mathrm{~s}, 5 \mathrm{~s}, 6 \mathrm{~s}\}$ 

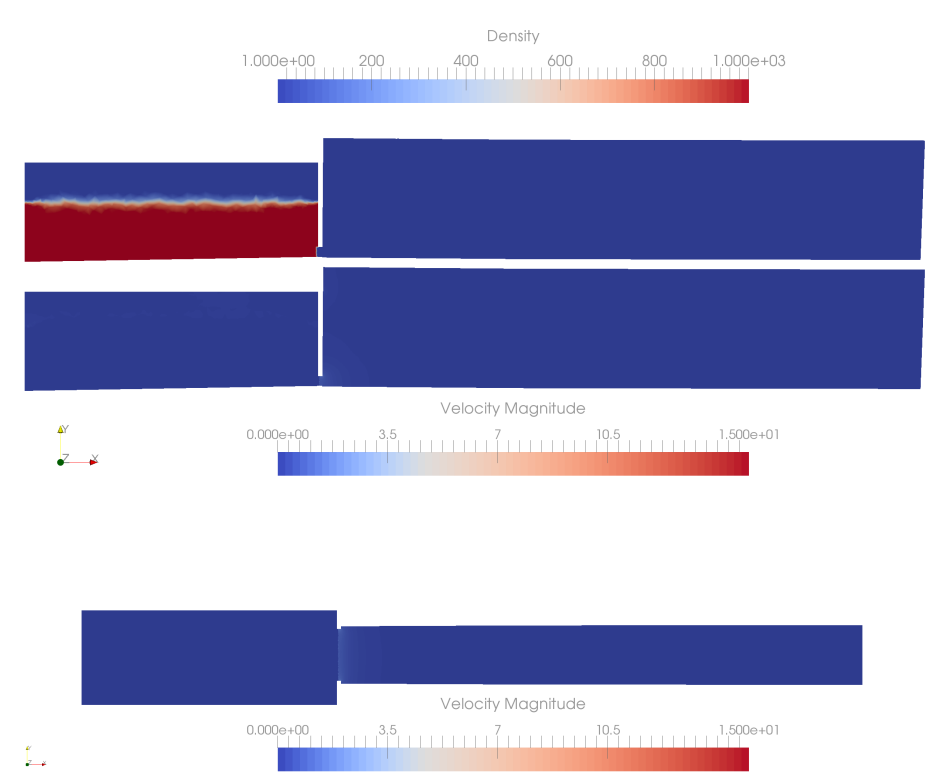

Figure 14: Density and velocity $\mathrm{x}-\mathrm{y}$ and $\mathrm{x}-\mathrm{z}$ slice $T_{D}=10 \mathrm{~s}, \mathrm{H}=6 \mathrm{~m}, \mathrm{t}=0 \mathrm{~s}$
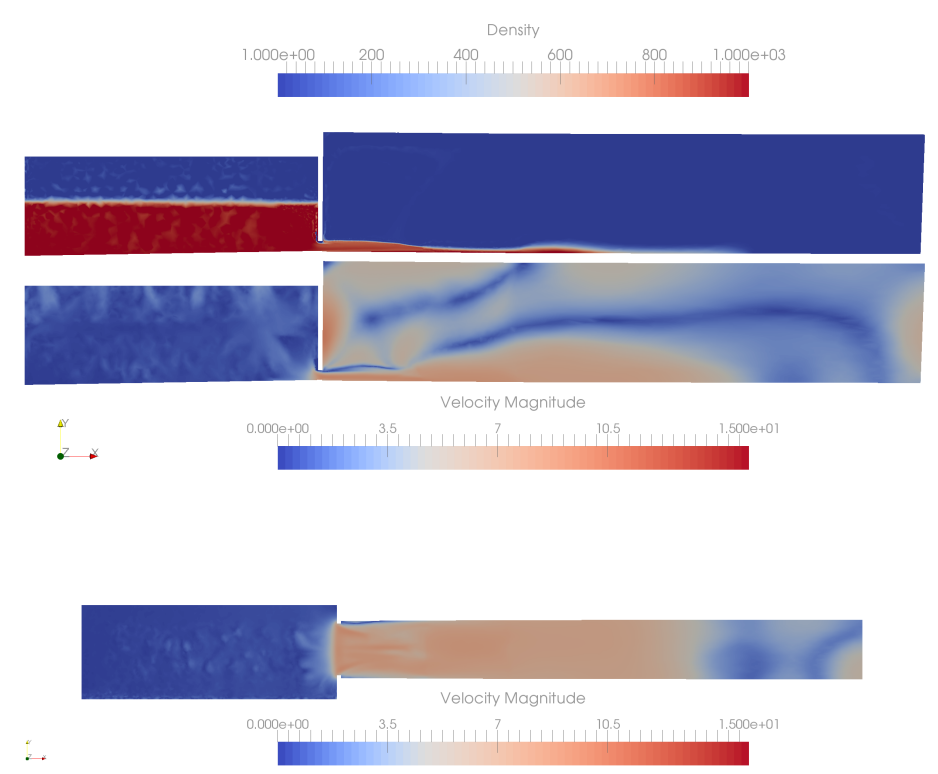

Figure 15: Density and velocity $\mathrm{x}-\mathrm{y}$ and $\mathrm{x}-\mathrm{z}$ slice $T_{D}=10 \mathrm{~s}, \mathrm{H}=6 \mathrm{~m}, \mathrm{t}=10 \mathrm{~s}$ 

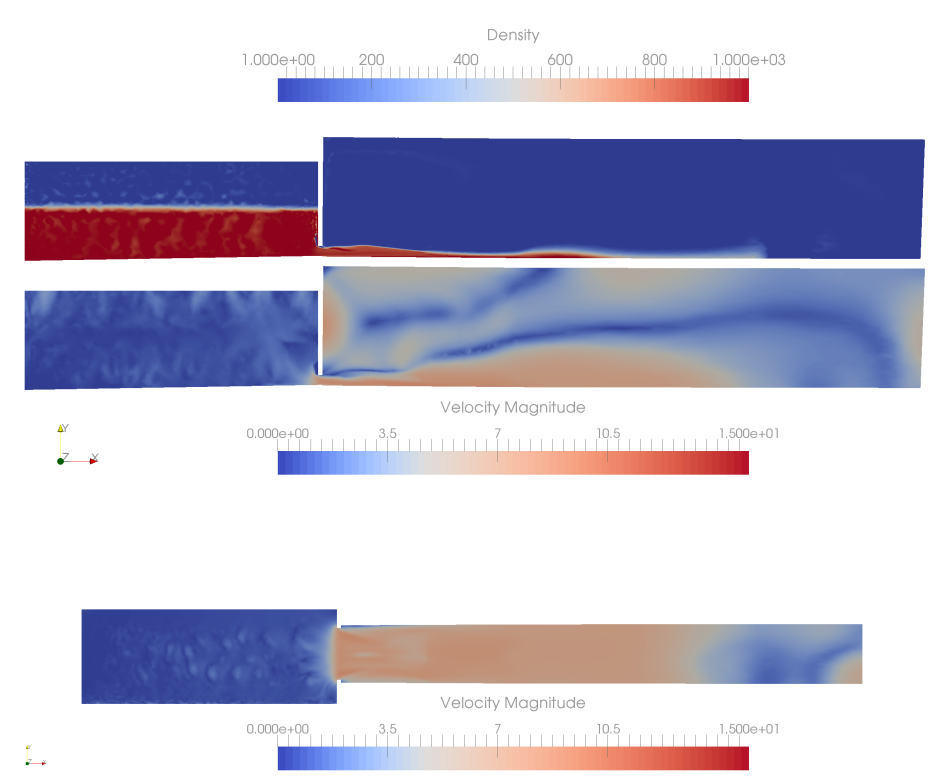

Figure 16: Density and velocity $\mathrm{x}-\mathrm{y}$ and $\mathrm{x}-\mathrm{z}$ slice $T_{D}=10 \mathrm{~s}, \mathrm{H}=6 \mathrm{~m}, \mathrm{t}=11 \mathrm{~s}$ 

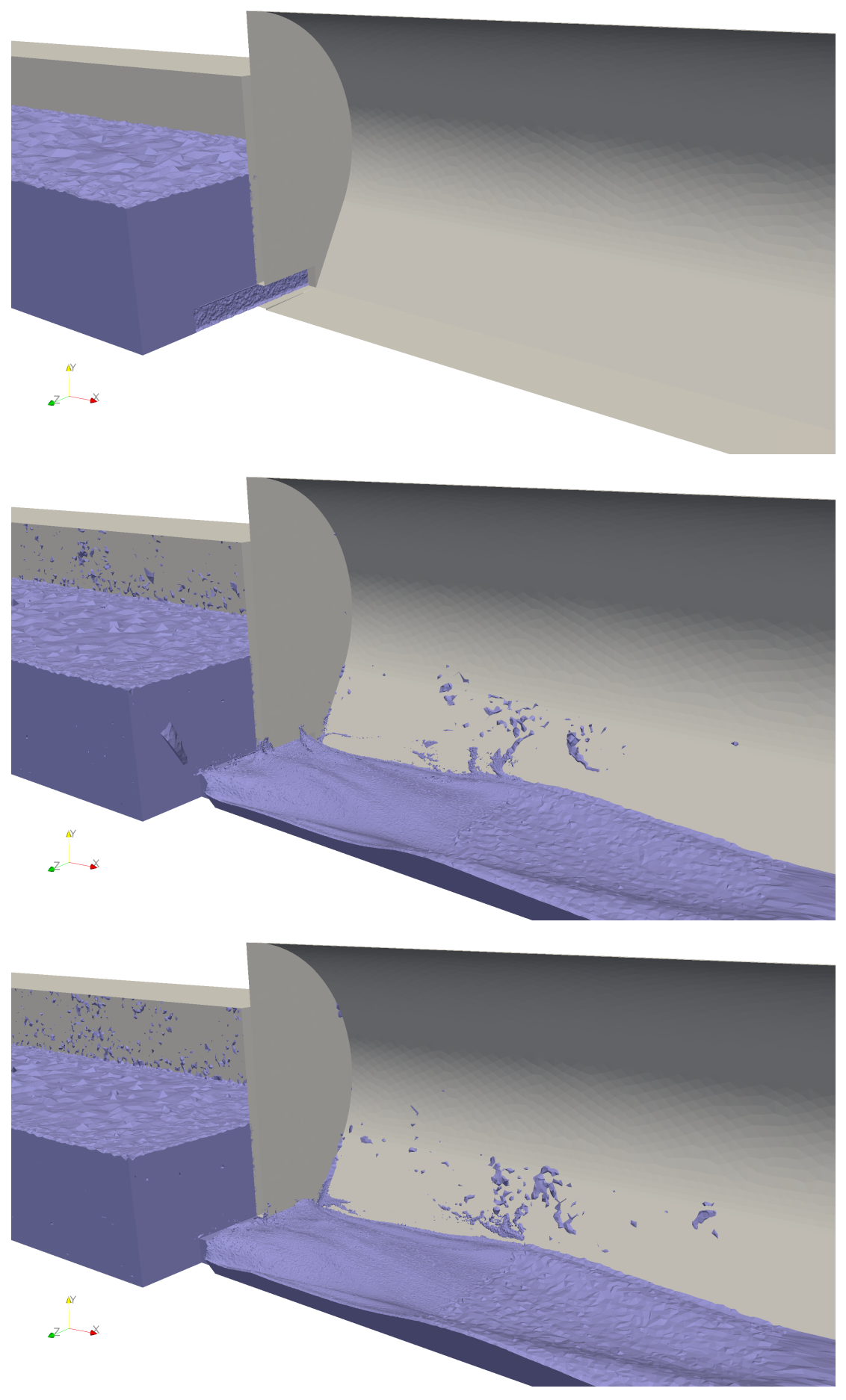

Figure 17: Water isovolume $T_{D}=10 \mathrm{~s}, \mathrm{H}=6 \mathrm{~m}, \mathrm{t}=\{0 \mathrm{~s}, 10 \mathrm{~s}, 11 \mathrm{~s}\}$ 

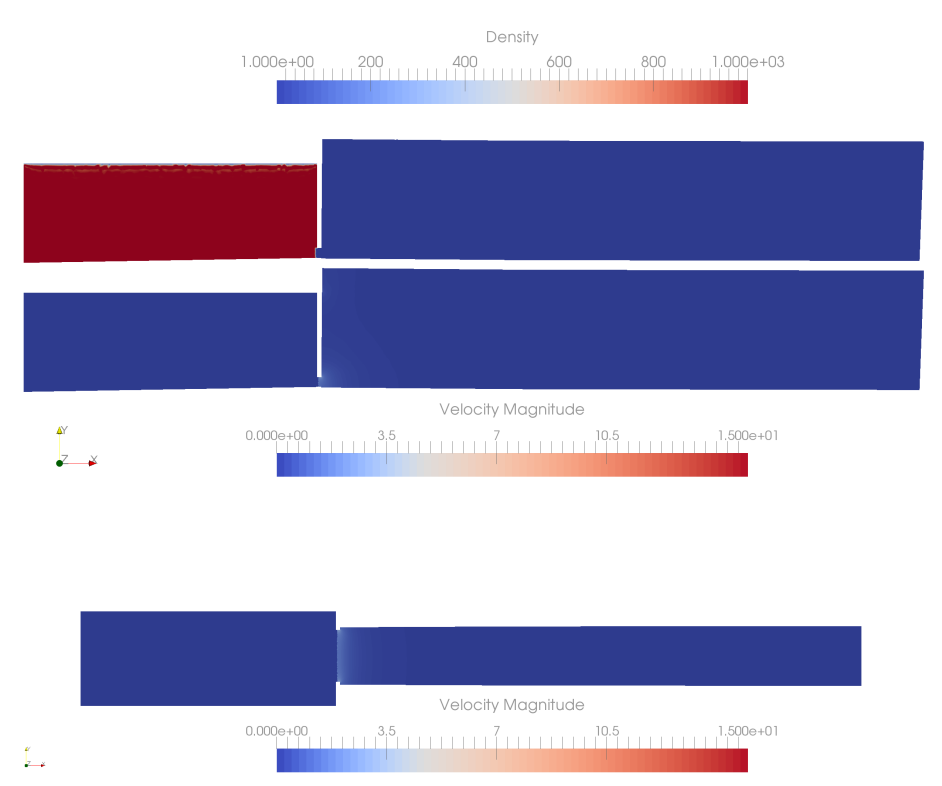

Figure 18: Density and velocity $\mathrm{x}-\mathrm{y}$ and $\mathrm{x}-\mathrm{z}$ slice $T_{D}=10 \mathrm{~s}, \mathrm{H}=10 \mathrm{~m}, \mathrm{t}=0 \mathrm{~s}$
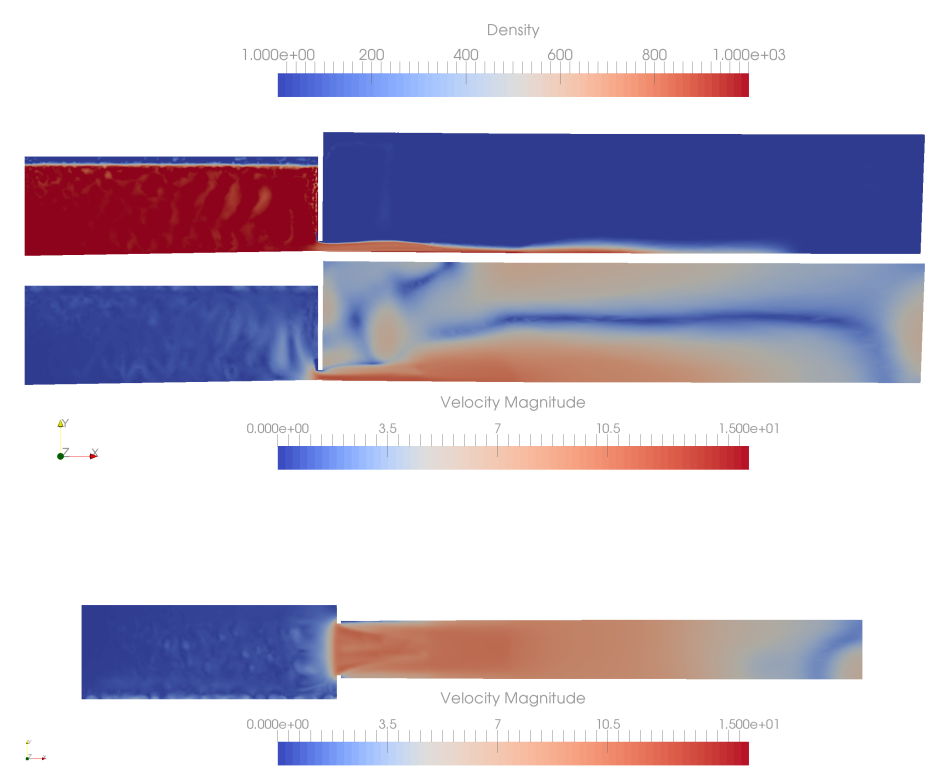

Figure 19: Density and velocity $\mathrm{x}-\mathrm{y}$ and $\mathrm{x}-\mathrm{z}$ slice $T_{D}=10 \mathrm{~s}, \mathrm{H}=10 \mathrm{~m}, \mathrm{t}=10 \mathrm{~s}$ 

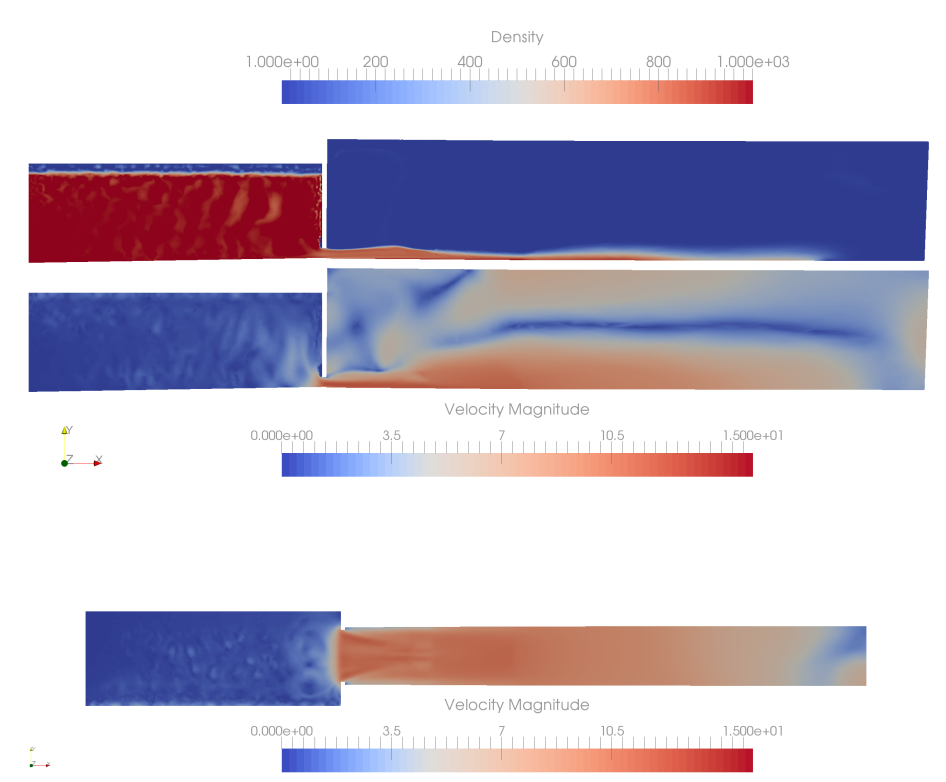

Figure 20: Density and velocity $\mathrm{x}-\mathrm{y}$ and $\mathrm{x}-\mathrm{z}$ slice $T_{D}=10 \mathrm{~s}, \mathrm{H}=10 \mathrm{~m}, \mathrm{t}=11 \mathrm{~s}$ 

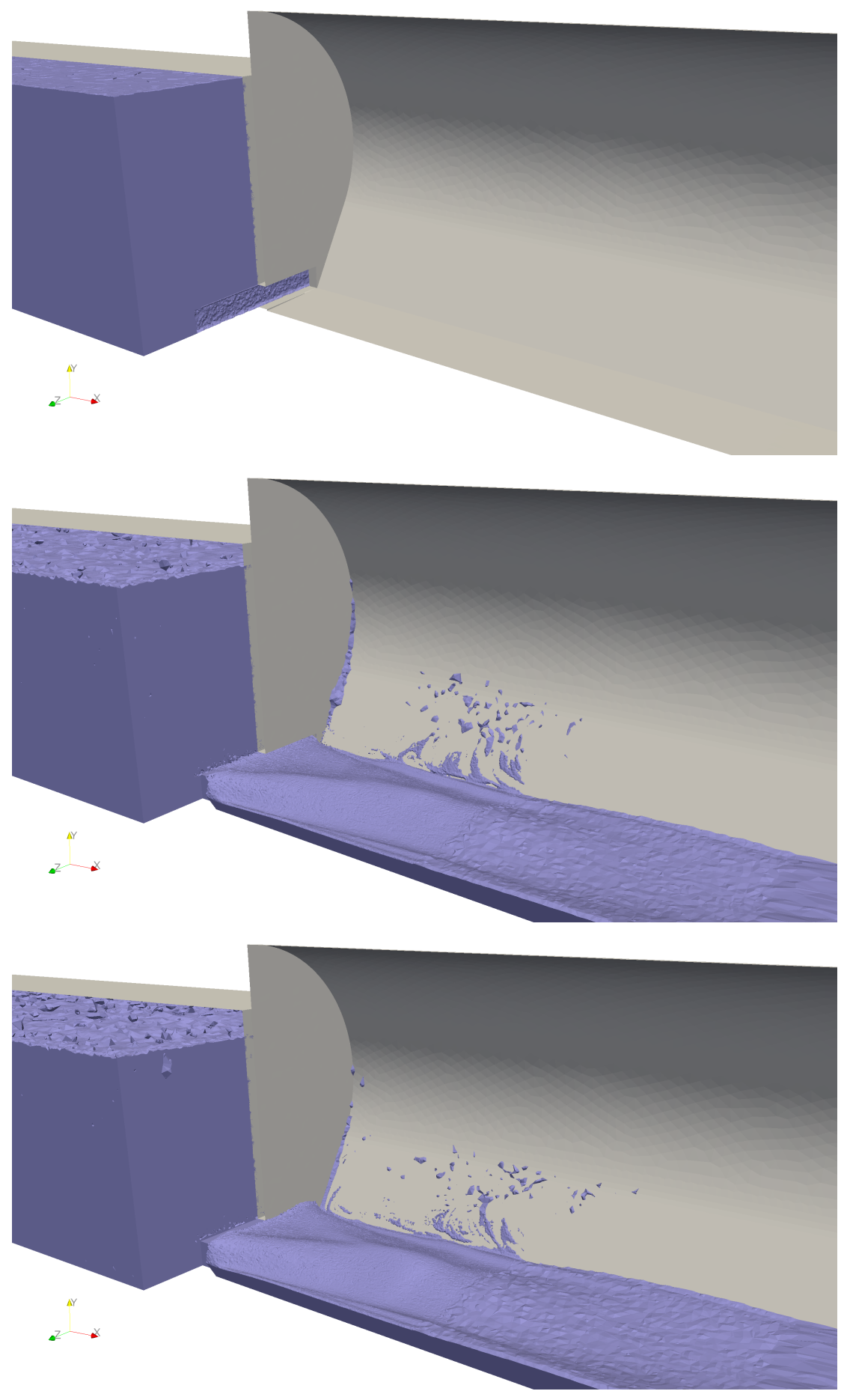

Figure 21: Water isovolume $T_{D}=10 \mathrm{~s}, \mathrm{H}=10 \mathrm{~m}, \mathrm{t}=\{0 \mathrm{~s}, 10 \mathrm{~s}, 11 \mathrm{~s}\}$ 
Figure 22 shows the flow rate through the gate. As we can see here, gate opening time and water height do have a influence over the water flow rate through the opening gate. Volumetric flow rate is depends on the area and the velocity. For example, in case $H=10 \mathrm{~m}$, when $T D=10 \mathrm{~s}$, the area of the flow through the gate is increasing slowly compare to $T D=5 \mathrm{~s}$, this shows, $T D=5 \mathrm{~s}$ reaches volumetric flow rate $50 \mathrm{~m}^{3} \mathrm{~s}^{-1}$ at 5 th second, whereas $T D=10$ s reaches volumetric flow rate $50 \mathrm{~m}^{3} \mathrm{~s}^{-1}$ at 10 th second. In general, if the $H$ is same (for $5 \mathrm{~s}$ and $10 \mathrm{~s}$ ) then the flow rate is depends on the area of the opening gate and if the $T D$ is same (for $6 \mathrm{~m}$ and $10 \mathrm{~m}$ ) then flow rate is depends on the velocity.
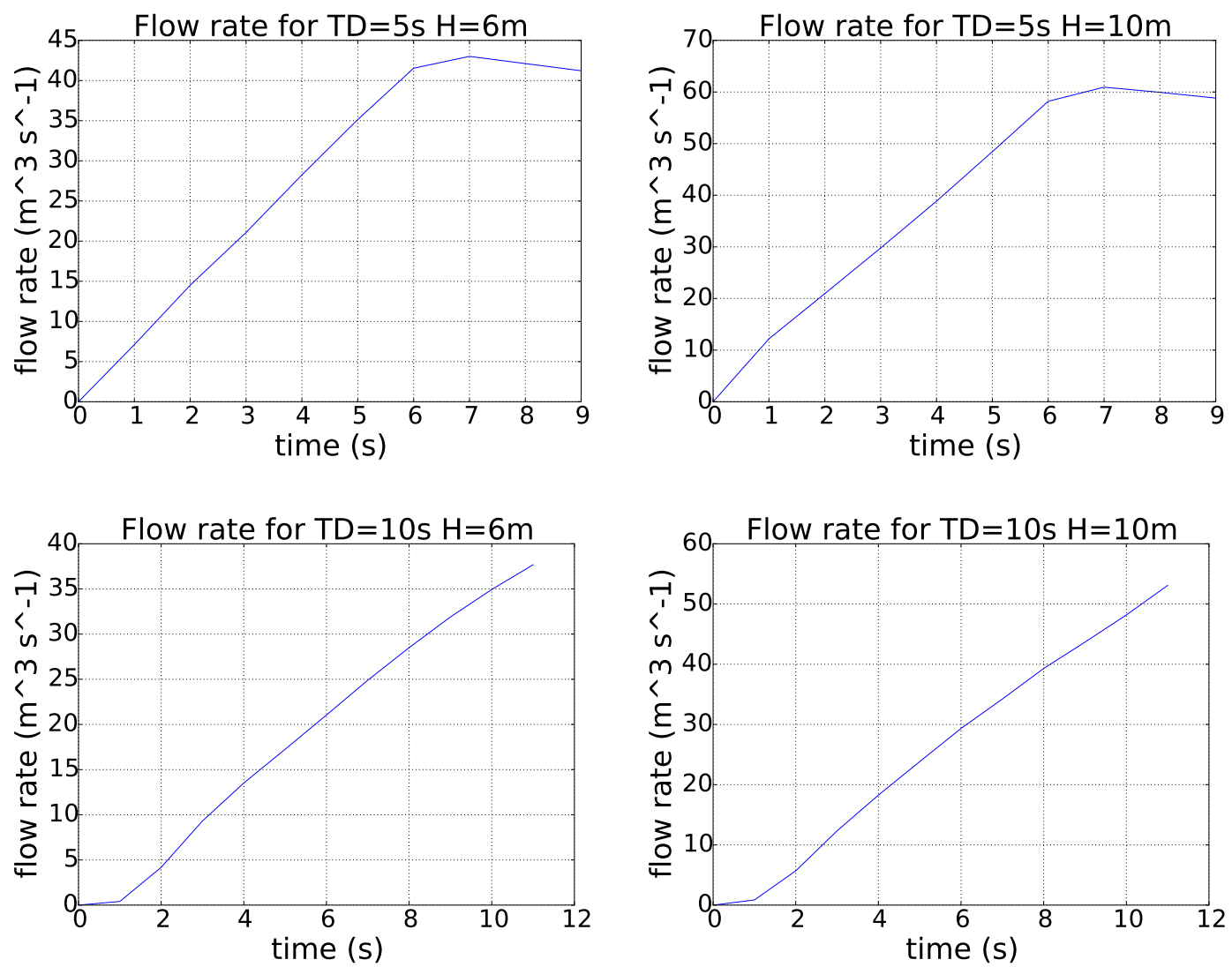

Figure 22: "Spending" flow rate through the door.

Figure 23 shows the average velocity at the door section. It is clearly understood that, velocity will be higher at the door section for $H=10 \mathrm{~m}$ compare to $H=6 \mathrm{~m}$ (for the same opening time $T D=5 \mathrm{~s}$ ). From Pascal's Law law we can calculate the static pressure at the gate, but in real case as gate opens we need to calculate the dynamic pressure, from this we can calculate the force acting on the door section. This will help to design a stronger door at the gate.

For example, static pressure can be expressed as $P=\rho g h \mathrm{~Pa}$, considering $H=10 \mathrm{~m}$, we get $\mathrm{P}=98.100 \mathrm{~Pa}$. Similarly the dynamic pressure at fully opened door can be calculated as $P=0.5 \rho v^{2}$. Velocity is around $10 \mathrm{~m} \mathrm{~s}^{-1}$ when the door is fully opened for $T D=5 \mathrm{~s}$ and $H=10 \mathrm{~m}$, from this the dynamic pressure will be $\mathrm{P}=490.500 \mathrm{~Pa}$. As we know force can be calculated from $F=p a \mathrm{~N}$. Area is $6 \mathrm{~m}^{2}$ and $\mathrm{P}=490.500 \mathrm{~Pa}$, the maximum acting force at the door will be $\mathrm{F}=2943 \mathrm{~N}$. 

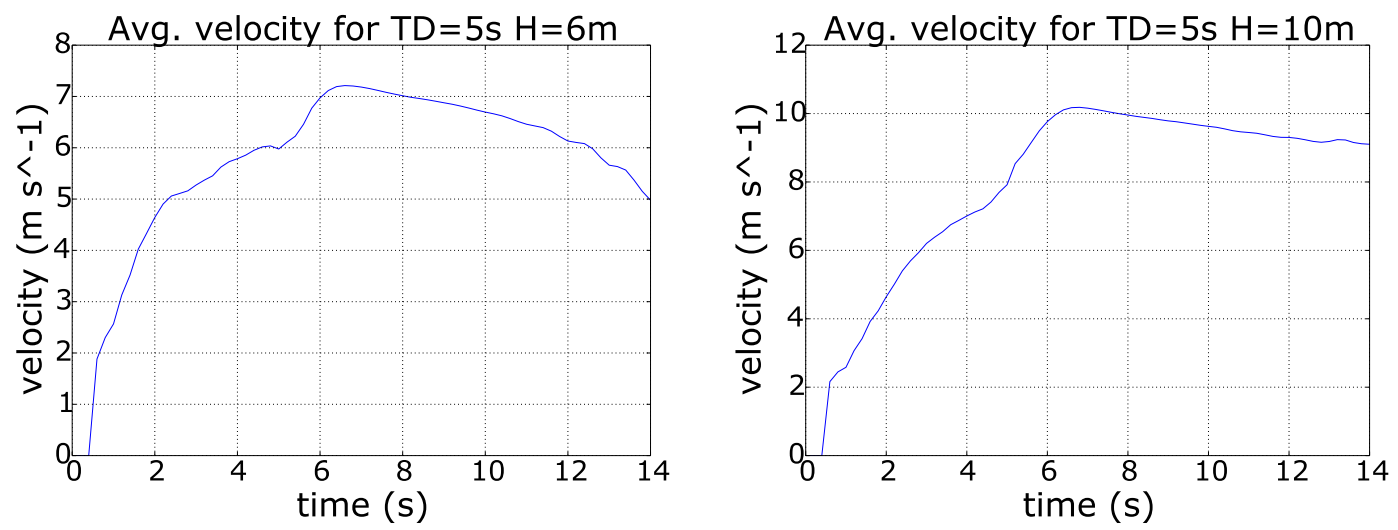

Figure 23: Average x-velocity in the door section.
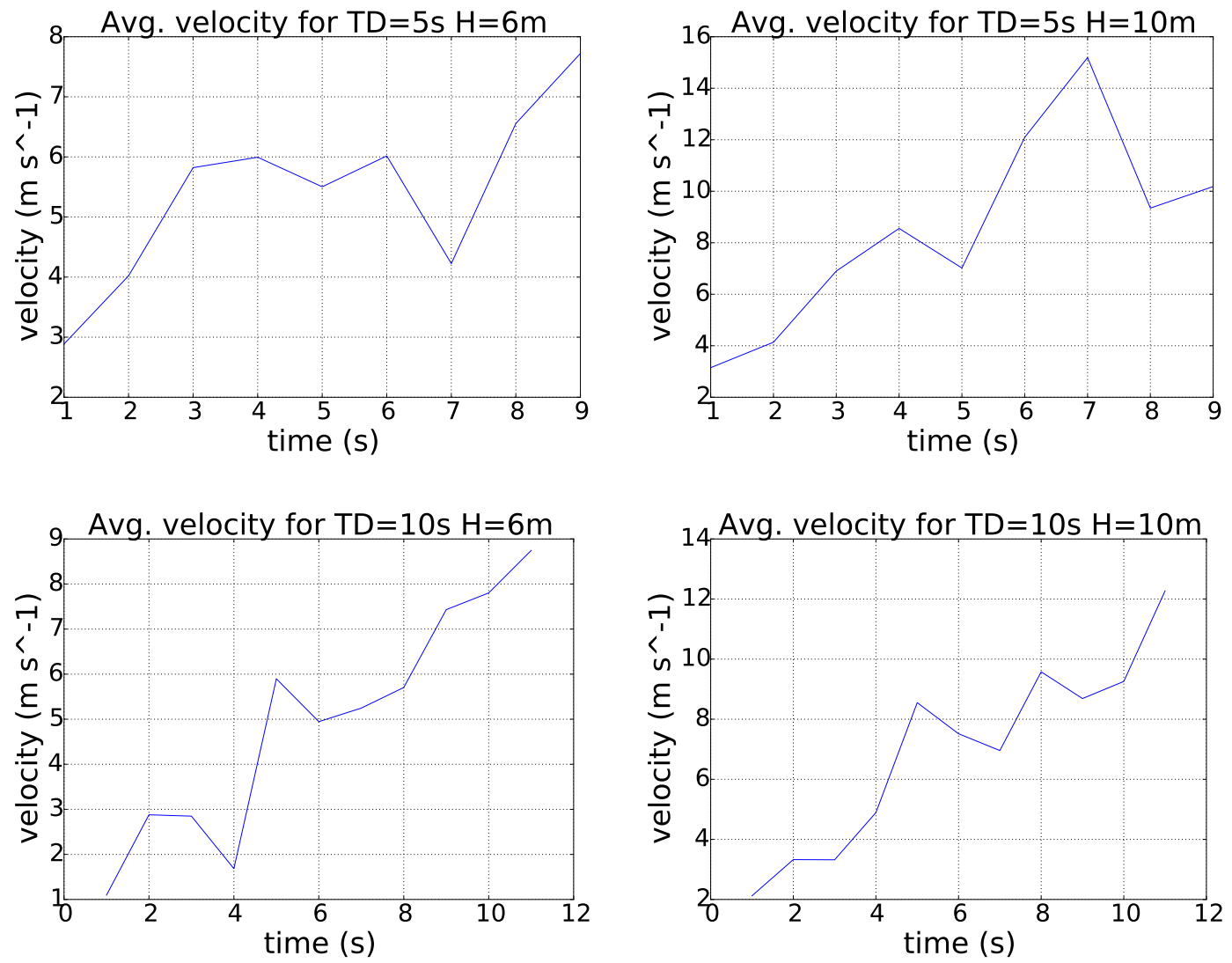

Figure 24: Average flushing x-velocity in the first 10m-section of the tunnel.

\section{Conslusions}

In this report we provide computational results for Direct FEM simulations of the primitive 3D variable-density incompressible Navier-Stokes equations. 
The density and velocity fields have a 3D structure, a triangular jet shape, at the exit of the door.

The door opening time does not appear to have a large influence on the structure or magnitude of the velocity.

The water height in the tank has a significant influence on the magnitude of the velocity in the flushing section at the beginning of the tunnel.

\section{REFERENCES}

[1] J Hoffman, J Jansson, RV de Abreu, NC Degirmenci, Niclas Jansson, Kaspar Mller, Murtazo Nazarov, JHiromi Sphler, Unicorn: Parallel adaptive finite element simulation of turbulent flow and fluid-structure interaction for deforming domains and complex geometry. Computers \& Fluids, 2013.

[2] J Hoffman, J Jansson, N Jansson, FEniCS-HPC: Automated predictive high-performance finite element computing with applications in aerodynamics, PPAM 2015. Lecture Notes in Computer Science, 2015.

[3] Jonkman, Sebastiaan N. Global perspectives on loss of human life caused by floods , Springer, 2005.

[4] The International Disaster Database. http://www.emdat.be.

[5] Füssel, Hans-Martin and Jol, André and others. Climate change, impacts and vulnerability in Europe 2012 an indicator-based report, Luxembourg: Publications Office of the European Union, 2012.

[6] Ezcurra, A and Areitio, J and Herrero, I. Relationships between cloud-to-ground lightning and surface rainfall during 1992-1996 in the Spanish Basque Country area. Atmospheric research, Elsevier, 2002.

[7] Johan Hoffman, Johan Jansson, Niclas Jansson, and Rodrigo Vilela De Abreu. To- wards a parameter-free method for high reynolds number turbulent flow simulation based on adaptive finite element approximation. Computer Methods in Applied Mechanics and Engineering, 288(0):60-74, 2015. Error Estimation and Adaptivity for Nonlinear and TimeDependent Problems.

[8] Johan Hoffman, Johan Jansson, and Claes Johnson. New theory of flight. Journal of Mathematical Fluid Mechanics, 2015.

[9] Johan Hoffman and Niclas Jansson. A computational study of turbulent flow separation for a circular cylinder using skin friction boundary conditions. Ercoftac, series Vol.16, Springer, 2010.

[10] Johan Hoffman and Claes Johnson. Resolution of dalemberts paradox. J. Math. Fluid Mech., Published Online First at www.springerlink.com: 10 December 2008.

[11] Rodrigo Vilela de Abreu, Niclas Jansson, and Johan Hoffman. Adaptive computation of aeroacoustic sources for a rudimentary landing gear. Int. J. Numer. Meth. Fluids, 74(6):406-421, 2014. 
[12] Johan Hoffman and Claes Johnson. Computational Turbulent Incompressible Flow: Applied Mathematics Body and Soul Vol 4. Springer-Verlag Publishing, 2006.

[13] Johan Hoffman and Claes Johnson. Computational Turbulent Incompressible Flow, volume 4 of Applied Mathematics: Body and Soul. Springer, 2007.

[14] U. Schumann. Subgrid-scale model for finite difference simulation of turbulent flows in plane channels and annuli. J. Comput. Phys., 18:376-404, 1975.

[15] Johan Hoffman. Computation of mean drag for bluff body problems using adaptive DNS/LES. SIAM J. Sci. Comput., 27(1):184-207, 2005.

[16] Johan Hoffman. Adaptive simulation of the turbulent flow past a sphere. J. Fluid Mech., 568:77-88, 2006.

[17] Johan Hoffman. Efficient computation of mean drag for the subcritical flow past a circular cylinder using general galerkin g2. Int. J. Numer. Meth. Fluids, 59(11):1241-1258, 2009.

[18] Johan Hoffman and Claes Johnson. A new approach to computational turbulence modeling. Comput. Methods Appl. Mech. Engrg., 195:2865-2880, 2006.

[19] Johan Hoffman, Johan Jansson, Rodrigo Vilela de Abreu, Niyazi Cem Degirmenci, Niclas Jansson, Kaspar Mller, Murtazo Nazarov, and Jeannette Hiromi Sphler. Unicorn: Parallel adaptive finite element simulation of turbulent flow and fluid- structure interaction for deforming domains and complex geometry. Computers and Fluids, 2012.

[20] Johan Hoffman, Johan Jansson, Cem Degirmenci, Niclas Jansson, and Murtazo Nazarov. Unicorn: a Unified Continuum Mechanics Solver, chapter 18. Springer, 2012.

[21] Niclas Jansson, Johan Hoffman, and Johan Jansson. Framework for Massively Parallel Adaptive Finite Element Computational Fluid Dynamics on Tetrahedral Meshes. SIAM J. Sci. Comput., 34(1):C24-C41, 2012.

[22] Robert C. Kirby. FIAT: Numerical Construction of Finite Element Basis Functions, chapter 13. Springer, 2012.

[23] Johan Hoffman, Johan Jansson, Niclas Jansson, C. Johnson, and Rodrigo V. de Abreu. Turbulent flow and fluid-structure interaction. In Automated Solutions of Differential Equations by the Finite Element Method. Springer, 2011.

[24] Johan Hoffman, Johan Jansson, Niclas Jansson, and Murtazo Nazarov. Unicorn: A unified continuum mechanics solver. In Automated Solutions of Differential Equations by the Finite Element Method. Springer, 2011.

[25] FEniCS. Fenics project. http://www.fenicsproject.org, 2003.

[26] Anders Logg, Kent-Andre Mardal, Garth N. Wells, et al. Automated Solution of Differential Equations by the Finite Element Method. Springer, 2012.

[27] J. Hoffman, J. Jansson, and M. Stckli. Unified continuum modeling of fluid-structure interaction. Mathematical Models and Methods in Applied Sciences, 2011. 
[28] Kees, C. E., Akkerman, I., Farthing, M. W., Bazilevs, Y. (2011). A conservative level set method suitable for variable-order approximations and unstructured meshes. Journal of Computational Physics, 230(12), 4536-4558.

[29] K.M.T. Kleefsman, G. Fekken, A.E.P. Veldman, B. Iwanowski and B. Buchner: A Volume-of-Fluid based simulation method for wave impact problems. J. Comp. Phys. 206 (2005) 363-393. 